University of Nebraska - Lincoln

DigitalCommons@University of Nebraska - Lincoln

Nebraska Cooperative Fish \& Wildlife Research Nebraska Cooperative Fish \& Wildlife Research Unit -- Staff Publications

2006

\title{
Multimodel Inference and the Understanding of Complexity, Discontinuity, and Normadism
}

\author{
Craig R. Allen \\ University of Nebraska-Lincoln, callen3@unl.edu \\ Denis A. Saunders \\ CSIRO Sustainable Ecosystems
}

Follow this and additional works at: https://digitalcommons.unl.edu/ncfwrustaff

Part of the Other Environmental Sciences Commons

\begin{abstract}
Allen, Craig R. and Saunders, Denis A., "Multimodel Inference and the Understanding of Complexity, Discontinuity, and Normadism" (2006). Nebraska Cooperative Fish \& Wildlife Research Unit -- Staff Publications. 24.

https://digitalcommons.unl.edu/ncfwrustaff/24
\end{abstract}

This Article is brought to you for free and open access by the Nebraska Cooperative Fish \& Wildlife Research Unit at DigitalCommons@University of Nebraska - Lincoln. It has been accepted for inclusion in Nebraska Cooperative Fish \& Wildlife Research Unit -- Staff Publications by an authorized administrator of DigitalCommons@University of Nebraska - Lincoln. 


\title{
Multimodel Inference and the Understanding of Complexity, Discontinuity, and Normadism
}

\author{
Craig R. Allen, ${ }^{1 *}$ and Denis A. Saunders ${ }^{2}$ \\ ${ }^{1}$ Nebraska Cooperative Fish and Wildlife Research Unit, US Geological Survey, University of Nebraska, Lincoln, Nebraska, USA; \\ ${ }^{2}$ CSIRO Sustainable Ecosystems, Canberra, Australian Capital Territory, Australia
}

\begin{abstract}
Nomadism has received surprisingly little attention in the ecological literature, and further work in this area is needed. The results of Woinarski's reanalysis of our research findings are broadly similar to our own, and they support our original interpretation. However, his presentation is confusing and difficult to interpret.We used an information-theoretic approach to multimodel selection. We a priori defined plausible candidate models relating the variables described in our original paper or Woinarski's reanalysis to the phenomenon of nomadism. We tested models that investigate nomadism as a function of nectivory, granivory, diet diversity, mixed diet, distance to body mass aggregation edge, mass, interactions between distance to edge and nectivory, distance to edge and mass, mass and nectivory, or mass and the interaction of edge and nectivory. There is consistency in our results across all sets of models, suggesting that mass, distance to
\end{abstract}

body mass aggregation (scale breaks), and diet (nectivory) are all important factors in determining nomadism. In no case was nectivory or any other diet variable supported in a single-variable model. Given the same data and similar results, we and Woinarski reach fundamentally different conclusions. Woinarski views nomadism as an easily understandable result given knowledge of the proper single mechanistic variable, and he discounts interactions with structural features of the landscape and scaling. We conclude that nomadism is a fundamentally complex phenomenon without a single source of causation, and that it is the interaction of species, species attributes, and landscapes that is responsible for nomadic behavior.

Key words: nomadism; birds; Australia; diet; information-theoretic approach; multimodel selection; complexity; discontinuity.

\section{INTRODUCTION}

We understand and sympathize with Woinarski's desire for ecological systems to be relatively simple and understandable. However, dynamic ecological systems often confound attempts at simplification. Decades of research has greatly enhanced our understanding of ecosystems as complex adaptive systems, characterized by nonlinear dynamics and

Received 6 April 2005; accepted 18 October 2005; published online 10 August 2006.

*Corresponding author; e-mail: rallen3@unlnotes.unl.edu interactions, thresholds, and sometimes unpredictable behaviors (for example, Levin 1998; Milne 1998). We now better, if still very incompletely, understand the role of scale, scale-specific processes, and discontinuity in ecological systems (Gunderson and Holling 2002).

We appreciate the reanalysis of our data provided by Woinarski in this issue, and welcome the opportunity for us to do the same. We do so by using methods of multimodel selection to clarify the ecological drivers of the complex behavior of nomadism. Nomadism has received surprisingly 
little attention in the ecological literature, and further work in this area is needed. Here we discuss the results and analysis of Woinarski and use information-theoretic methods for multimodel selection to analyze the data provided in his critical commentary.

Woinarski states that the assignation of diets in our earlier paper (Allen and Saunders 2002) was incorrect, and that there were errors of transcription from our primary source (Schodde 1981). He is correct that our assignation of diet differed from that of Schodde; however, this is because our primary source for this information was Saunders and Ingram (1995). Nevertheless, our assignation of diet was oversimplified, and the more thorough breakdown provided by Woinarski is useful and welcome.

Woinarski uses significance testing to determine the simplest possible explanation of nomadism. If nomadism were a simply understood phenomenon, this approach, would be useful; but nomadism is a complex phenomenon, as Woinarski's reanalysis of our earlier data confirms. Woinarski built eight models of predictors of nomadism, using backward selection generalized linear modeling; these methods are similar to the ones originally used by us (Allen and Saunders 2002). The primary difference between our original analysis and Woinarski's reanalysis lies in the use of some different categorizations of diet, including a mixeddiet classification, and the compression of the different classes of diet used in our study into a single, presumably categorical, variable. His results are broadly similar to our own. In four of the eight models presented by Woinarski, the variables "distance to edge" and "diet" are both significant. In two models, only diet is significant; in one model, there are no significant predictors; and in one model, diet is significant and distance to edge and mass are nearly so. We believe that those results support our original contention and our interpretation of the data.

However, the presentation of his results is difficult to interpret. No overall measures of model fit are presented. Diet is presented as a single variable, so it is not possible to interpret what it is about diet that may influence nomadism. Woinarski asserts that nomadism is most prevalent among species that rely on nectar for their primary diet, but this is not apparent from the results presented. Nor is it clear how minimum adequate models were selected, other than the invocation of Occams's razor. In some cases, variables with lower $P$ values in the original model (for example, weight in Woinarski's fourth model) are not present in the minimum adequate model. At minimum, what is or is not a minimum adequate model needs to be assessed with a chi-square test of lack of fit.

Presumably, models with a mixed-diet classification have one more category of diet present in the model (that is, the four diet classes plus an additional mixed class), and this should be reflected with an additional degree of freedom for the diet variable. This is not the case, and all models are listed with four degrees of freedom. We assume percent of deviation explained is a way of stating $r^{2}$, but $r^{2}$ is appropriate only with linear regression, not logistic regression. Instead, odds ratios should be reported, as we did in our original publication. Finally, Woinarski provides no model solution as we did, further obscuring any attempt to understand the results as presented.

Woinarski views our approach as overly complicated, stating that it is focused on some "disorder in the numerological fabric of the weights of species, the individual components of a tightly engineered and organized system." Clearly, Woinarski would prefer that complex systems and behaviors be driven by single causative mechanisms. We did not and do not suggest that species are components of a tightly engineered and organized system. Rather, we believe the opposite-that ecosystems are organized as complex systems, with elements of both disorder and order.

Given our difficulty in interpreting his results as presented, and his somewhat different classification of diet, we present in this paper a reanalyis of the data provided by Woinarski. To do so, we used an information-theoretic approach to multimodel selection.

\section{MethodS}

We accept the data as presented by Woinarski, because it is not our intention to argue further over data. To those data we add a variable on diet diversity, which corresponds to the number of different items in a specie's diet. As such, it is a finer-level breakdown of the mixed-diet class of Woinarski. Data for that variable were transcribed from Saunders and Ingram (1995), except for the following species, which were classified based on Blakers and others (1984): little raven (Corvus mellori), yellow thornbill (Acanthiza nana), buffrumped thornbill (A. reguloides), striated grasswren (Amytornis striatus), brown treecreeper (Climacteris picumnus), chestnut-crowned babbler (Pomatostomus ruficeps), gray shrike-thrush (Colluricincla harmonica), Australian magpie lark (Grallina cyanoleuca), spine-tailed swift (Hirundapus caudacutus), 
white-winged chough (Corcorax melanorhamphos), white-browed woodswallow (Artamus superciliosus), musk lorikeet (Glossopsitta concinna), rainbow lorikeet (Trichoglossus haematodus), blue-winged parrot (Neophema chrysostoma), peaceful dove (Geopelia placida), red-rumped parrot (Psephotus haematonotus), blue bonnet (Northiella haematogaster), mallee ringneck (Barnardius barnardi), and glossy black cockatoo (Calyptorhynchus lathami).

We used an information-theoretic approach to multimodel selection. We a priori defined plausible candidate models relating the variables described in our original paper (Allen and Saunders 2002) or by Woinarski in this issue to the phenomenon of nomadism. Information-theoretic methods depend on the selection of a limited subset of plausible models; they differ from multiple regression methods, which have been criticized as datadredging. In addition, hypothesis-testing approaches such as stepwise regression determine a variable to be important or unimportant depending on whether or not it is included in the final 'significant' model, which can be misleading (Anderson and others 2000; Burnham and Anderson 2002).

The models we consider are (a) nomadic $=$ nectar, (b) nomadic $=$ seed, $($ c) nomadic $=$ dietdiversity, (d) nomadic $=$ edgedistance, $\quad$ (e) nomadic $=$ mixed (only for the Woinarski classification using five diet categories), (f) nomadic $=$ mass, $\quad($ g) nomadic $=$ edge*nectar,$\quad(\mathrm{h})$ nomadic $=$ edge ${ }^{*}$ mass, $\left(\right.$ i) nomadic $=$ mass ${ }^{*}$ nectar , and $(\mathrm{j})$ nomadic $=$ mass edge ${ }^{*}$ nectar .

That is, nomadism may be a function of a nectivorous diet, a seed diet, level of diet diversity, mixed diet, distance to a body mass aggregation edge, mass, interactions between distance to edge and nectivory, distance to edge and mass, mass and nectivory, or mass and the interaction of edge and nectivory.

We evaluated competing models based on the use of Akaike's information criterion (AIC), with lowest values indicating the best model fit and differences of AIC ( $\triangle \mathrm{AIC})$ of less than 2 indicating equally supported models. Models with $\triangle$ AIC values of greater than 12 indicate models with virtually no empirical support. The purpose of this approach is to select the "best approximating model" (Burnham and Anderson 2002) for statistical inference. We contend that nomadism is poorly understood and believe that early investigations of poorly understood complex phenomena should minimize type II error prior to shifting focus on candidate models and attempting to minimize type I error (Holling and Allen 2002). Among their other advantages, information-theoretic approaches remove model selection uncertainty from the modeling process. Additionally, we provide model weights $\left(W_{i}\right)$, which normalize the relative likelihood of a model, which may be interpreted as the weight of evidence in favor of a particular model given the tested subset of models (Burnham and Anderson 2002).

We used this approach for four different data sets. Two data sets were based on the definition of nomadism provided by Schodde (1981), and two were based on the definition of nomadism as provided by Saunders and Reid and presented in our original paper (Allen and Saunders 2002). Within each definition of nomadism, we built two sets of models based on the data presented in Woinarski's reanalysis-one based on a four-class categorization of diet and one with a five-class categorization, including a mixed-diet category. We did not model the 132-species assemblage of Woinarski because no data on mass were given for those additional 8 species and because there were only trivial differences between the 124-species and 132-species analyses in the results presented by Woinarski.

\section{Results}

Using information-theoretic methods of multimodel selection, we found broadly consistent results across all four sets of models. Using the Saunders classification of nomadism, there was no single best fit model. Using Woinarski's four-class categorization of diet, there were four plausible models. In each plausible model, distance to body mass aggregation edge was an included variable: the model with only distance to edge as a predictor, the models with edge-nectivory and edge-body mass interactions, and the model with mass and an edge-nectivory interaction (Table 1).

Using the Saunders classification of nomadism and the five-class categorization of diet provided by Woinarski, and including an additional mixed-diet model, two candidate models were supported. Both of them included distance to body mass aggregation edge as a predictor of nomadism. However, both models included interaction terms between distance to body mass aggregation and nectivory, and both models were also supported using the fourclass categorization of diet provided by Woinarski (Table 2).

Single models were supported using the classification of nomadism as provided by Schodde (1981) (Table 3), for both the four- and five-class categorization of diet provided by Woinarski (Table 4 ). Here, the single model nomadism $=$ mass 
Table 1. Analysis with Saunder's Classification of Nomadism and Woinarski's Four-Class Categorization of Diet

\begin{tabular}{|c|c|c|c|c|c|c|}
\hline Model Parameters & No. of Parameters & Estimate & SE & AIC & $\Delta \mathrm{AIC}$ & $W_{i}$ \\
\hline Nectar & 2 & -1.19 & 0.84 & 125.80 & 4.38 & 0.03 \\
\hline Dietdiversity & 2 & -0.15 & 0.16 & 124.80 & 3.38 & 0.05 \\
\hline Seed & 2 & 0.28 & 0.60 & 125.62 & 4.20 & 0.03 \\
\hline Edge & 2 & -1.20 & 0.67 & 121.79 & 0.37 & 0.22 \\
\hline Mass & 2 & 0.14 & 0.33 & 125.67 & 4.25 & 0.03 \\
\hline Edge*nectar & 2 & -0.65 & 0.35 & 121.42 & 0.00 & 0.27 \\
\hline Mass*nectar & 2 & -0.06 & 0.16 & 125.72 & 4.30 & 0.03 \\
\hline Edge*mass & 2 & -0.63 & 0.37 & 121.81 & 0.39 & 0.22 \\
\hline Mass edge*nectar & 3 & & & 123.08 & 1.66 & 0.12 \\
\hline (Mass) & & 0.19 & 0.33 & & & \\
\hline$($ Edge*nectar $)$ & & -0.65 & 0.35 & & & \\
\hline
\end{tabular}

Intercepts were fit in all models. Selection criterion is Akaike's information criterion (AIC). The best-supported models are in bold, as assessed by $\Delta A I C<2$. Akaike weights (Wi) assess the relative likelihood of a model.

Table 2. Analysis with Saunder's Classification of Nomadism and Woinarski's Five-Class Categorization of Diet

\begin{tabular}{|c|c|c|c|c|c|c|}
\hline Model Parameters & No. of Parameters & Estimate & SE & AIC & $\Delta \mathrm{AIC}$ & $W_{i}$ \\
\hline Nectar & 2 & No estimate $^{1}$ & & & & \\
\hline Dietdiversity & 2 & -0.15 & 0.16 & 124.80 & 5.47 & 0.03 \\
\hline Mixed & 2 & 0.04 & 0.69 & 125.85 & 6.52 & 0.02 \\
\hline Seed & 2 & -0.25 & 0.57 & 125.66 & 6.33 & 0.02 \\
\hline Edge & 2 & -1.20 & 0.67 & 121.79 & 2.46 & 0.13 \\
\hline Mass & 2 & 0.14 & 0.33 & 125.67 & 6.34 & 0.02 \\
\hline Edge*nectar & 2 & -0.83 & 0.38 & 119.33 & 0.00 & 0.45 \\
\hline Mass*nectar & 2 & -0.11 & 0.17 & 125.45 & 6.12 & 0.02 \\
\hline Edge*mass & 2 & -0.63 & 0.37 & 121.81 & 2.48 & 0.13 \\
\hline Mass edge*nectar & 3 & & & 121.01 & 1.68 & 0.19 \\
\hline (Mass) & & 0.19 & 0.33 & & & \\
\hline (Edge*nectar) & & -0.83 & 0.38 & & & \\
\hline
\end{tabular}

Intercepts were fit in all models. Selection criterion is AIC. The best-supported models are in bold, as assessed by $\triangle A I C<2$. Akaike weights (W $W_{i}$ assess the relative likelihood of a model.

${ }^{1}$ Quasi-complete separation of data points prevents maximum likelihood estimate.

Table 3. Analysis with Schodde's (1981) Classification of Nomadism and Woinarski's Four Class Categorization of Diet

\begin{tabular}{|c|c|c|c|c|c|c|}
\hline Model parameters & No. of parameters & Estimate & SE & AIC & $\Delta \mathrm{AIC}$ & $W_{i}$ \\
\hline Nectar & 2 & -0.26 & 0.70 & 169.39 & 21.16 & 0.00 \\
\hline Dietdiversity & 2 & 0.17 & 0.12 & 167.30 & 19.07 & 0.00 \\
\hline Seed & 2 & -0.07 & 0.46 & 169.50 & 21.27 & 0.00 \\
\hline Edge & 2 & -0.92 & 0.46 & 164.98 & 16.75 & 0.00 \\
\hline Mass & 2 & 1.14 & 0.32 & 154.35 & 6.12 & 0.05 \\
\hline Edge*nectar & 2 & -0.48 & 0.24 & 164.72 & 16.49 & 0.00 \\
\hline Massnectar & 2 & 0.47 & 0.14 & 157.41 & 9.18 & 0.01 \\
\hline Edge*mass & 2 & -0.11 & 0.18 & 169.11 & 20.88 & 0.00 \\
\hline Mass edge*nectar & 3 & & & 148.23 & 0.00 & 0.94 \\
\hline (Mass) & & 1.34 & 0.34 & & & \\
\hline (Edge*nectar) & & -0.64 & 0.25 & & & \\
\hline
\end{tabular}

Intercepts were fit in all models. Selection criterion is AIC. The best-supported models are in bold, as assessed by $\triangle A I C<2$. Akaike weights ( $\left.W_{i}\right)$ assess the relative likelihood of a model. 
Table 4. Analysis with Schodde's (1981) Classification of Nomadism and Woinarski's Five Class Categorization of Diet

\begin{tabular}{|c|c|c|c|c|c|c|}
\hline Model Parameters & No. of parameters & Estimate & SE & AIC & $\Delta \mathrm{AIC}$ & $W_{i}$ \\
\hline Nectar & 2 & & & No estimate $^{1}$ & & \\
\hline Dietdiversity & 2 & 0.17 & 0.12 & 167.30 & 20.17 & 0.00 \\
\hline Mixed & 2 & -0.24 & 0.54 & 169.33 & 22.20 & 0.00 \\
\hline Seed & 2 & -0.56 & 0.47 & 168.12 & 20.99 & 0.00 \\
\hline Edge & 2 & -0.92 & 0.46 & 164.98 & 17.95 & 0.00 \\
\hline Mass & 2 & 1.14 & 0.32 & 154.35 & 7.22 & 0.03 \\
\hline Edge*nectar & 2 & -0.54 & 0.24 & 163.67 & 16.54 & 0.00 \\
\hline Mass*nectar & 2 & 0.42 & 0.14 & 159.95 & 12.82 & 0.00 \\
\hline Edge*mass & 2 & -0.11 & 0.18 & 169.11 & 21.98 & 0.00 \\
\hline Mass edge*nectar & 3 & & & 147.13 & 0.00 & 0.97 \\
\hline (Mass) & & 1.35 & 0.35 & & & \\
\hline (Edge*nectar) & & -0.70 & 0.25 & & & \\
\hline
\end{tabular}

Intercepts were fit in all models. Selection criterion is AIC. The best-supported models are in bold, as assessed by $\triangle A I C<2$. Akaike weights (Wi) assess the relative likelihood of a model.

${ }^{1}$ Quasi-complete separation of data points prevents maximum likelihood estimate.

edge*nectar was supported, indicating the importance of mass, whereby larger species are more likely to be nomadic, as well as the interaction between distance to body mass aggregation edge and nectivory.

\section{Discussion}

We appreciate and embrace divergent interpretations of the drivers of the complex phenomenon of nomadism. This behavior and its multiple causative factors clearly warrant more attention than has been provided in the literature to date. Dissenting views may enable us to unravel more effectively the drivers of complexity and complex behaviors in these systems. That being said, complex systems such as ecosystems are by definition not simple, nor necessarily easily understood, and are unlikely to be driven by single mechanisms of causations, such as diet, or by simple linear chains of causation.

There is broad consistency in our results, suggesting that mass, distance to body mass aggregation (scale breaks), and diet (nectivory) are all important in determining nomadism. In only one case was a single-variable model without interaction supported (distance to body mass aggregation edge) (Table 1). All other models included interactions, and the most consistently supported model included body mass and the interaction between distance to a body mass aggregation edge and nectivory. In no case was nectivory or any other diet variable supported in a single-variable model.

Given the same data, and what we believe to be similar though not identical results, we and Woinarski reach fundamentally different conclu- sions. Woinarski concludes that nomadism is a phenomenon that can be understood by knowing a species' diet and little else. This view treats nomadism, and presumably other complex phenomenon such as migration, as easily understandable results given knowledge of the proper single mechanistic variable, and discounts interactions with structural features of the landscape as well as scaling. Our analysis suggests that nomadism is a fundamentally complex phenomenon without a single source of causation, and that it is the interaction of species, including attributes of species such as body mass and diet, with landscapes, including scale-specific structuring of landscapes and mesoscale climatic patterns, that are responsible for driving the behavior of nomadism. We believe that the generation of novel behaviors, such as nomadism and migration, has its roots in interactions among a variety of processes operating at distinctly different scales. We and Woinarski clearly have differing assumptions regarding the structure and function of ecosystems, and the interaction of animals with their environments. His methods search for the simplicity of minimum models; we expect ecosystems to be both complex and complicated.

A pattern is emerging regarding the relationship between discontinuities and variability in complex systems. We have documented a relationship between proximity to discontinuities in body mass distributions and the invasion of new species (Allen and others 1999), species decline (Allen and others 1999), nomadism (Allen and Saunders 2002, this paper; Woinarski this issue), and migration (Weeks unpublished). We hypothesize that resources are 


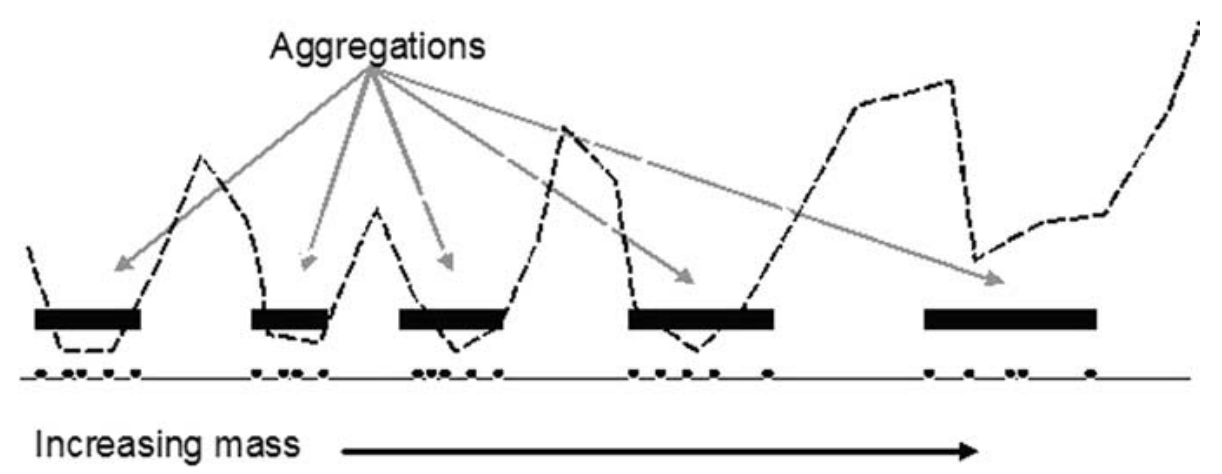

Figure 1. A conceptual model of the relationship between body mass aggregations, discontinuities, and variability in resources. A hypothetical species body mass distribution is shown on a body mass axis, with the mass of individual species displayed as filled circles. Aggregations of species (dark bars) correspond to clusters of species separated by discontinuities. The dashed line represents the predicted relationship between discontinuities and resource variability in space and time. High variability exists at discontinuities, hypothesized to be scale breaks. It is at the edge of these discontinuities that novelty is most likely to arise, as assessed by biological phenomena such as invasions, migration, and nomadism.

most variable at discontinuities in body mass distributions, (Figure 1) and most stable within body mass aggregations. The edge of discontinuities provides the requisite stressful dichotomy between abundance and paucity that leads to the generation of novelty-novelty that may include the invasion of new species and such behaviors, as migration and nomadism.

\section{ACKNOWLEDGEMENTS}

Support was provided by the James S. McDonnell Foundation $21^{\text {st }}$ Century Research Award/Studying Complex Systems (C. R. A). The Nebraska Cooperative Fish and Wildlife Research Unit is jointly supported by a cooperative agreement among the USGS/BRD, the Nebraska Game and Parks Commission, the University of Nebraska, the US Fish and Wildlife Service, and the Wildlife Management Institute. This paper was improved by incorporating comments from E. Blankenship and A. Tyre.

\section{REFERENCES}

Allen CR, Forys EA, Holling CS. 1999. Body mass patterns predict invasions and extinctions in transforming landscapes. Ecosystems 2:114-21.
Allen CR, Saunders DA. 2002. Variability between scales: predictors of nomadism in birds of an Australian Mediterraneanclimate ecosystem. Ecosystems 5:348-59.

Anderson DR, Burnham KP, Thompson WL. 2000. Null hypothesis testing: problems, prevalence, and an alternative. $J$ Wildl Manage 64:912-23.

Blakers M, Davies SJJF, Reilly PN. 1984. The atlas of Australian birds. Carlton, (Aust.): Melbourne University Press.

Burnham KP, Anderson DR. 2002. Model selection and multimodel inference: a practical information-theoretic approach. 2nd ed. Berlin Heidelberg New York: Springer.

Gunderson LH, Holling CS. 2002. Panarchy: understanding transformations in human and natural systems. Washington, (DC): Island Press.

Holling CS, Allen CR. 2002. Adaptive inference for distinguishing credible from incredible patterns in nature. Ecosystems 5:319-28.

Levin SA. 1998. Ecosystems and the biosphere as complex adaptive systems. Ecosystems 1:431-6.

Milne BT. 1998. Motivation and benefits of complex systems approaches in ecology. Ecosystems 1:449-56.

Saunders DA, Ingram JA. 1995. Birds of southwestern Australia: an atlas of changes in distribution and abundance of the wheatbelt avifauna. Chipping Norton, (Aust.): Surrey Beatty \& Sons.

Schodde R. 1981. Bird communities of the Australian mallee: composition, derivation, distribution, structure and seasonal cycles. In: di Castri F, Goodall DW, Specht RL, Eds. Mediterranean-type shrublands. New York: Elsevier Scientific. pp 387-415. 